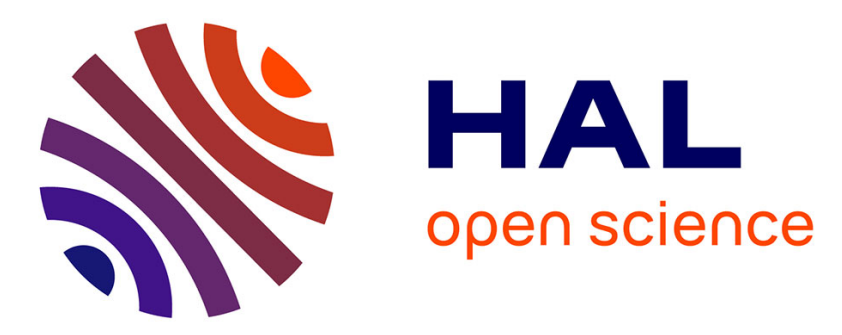

\title{
Tachyoryctes makooka (Tachyoryctini, Spalacidae, Rodentia) and its bearing on the phylogeny of the Tachyoryctini
}

\author{
Raquel López-Antoñanzas, Henry Wesselman
}

\section{To cite this version:}

Raquel López-Antoñanzas, Henry Wesselman. Tachyoryctes makooka (Tachyoryctini, Spalacidae, Rodentia) and its bearing on the phylogeny of the Tachyoryctini. Palaeontology, 2013, 56 (1), pp.157 - 166. 10.1111/j.1475-4983.2012.01179.x . hal-01920784

\section{HAL Id: hal-01920784 \\ https://hal.science/hal-01920784}

Submitted on 28 Dec 2020

HAL is a multi-disciplinary open access archive for the deposit and dissemination of scientific research documents, whether they are published or not. The documents may come from teaching and research institutions in France or abroad, or from public or private research centers.
L'archive ouverte pluridisciplinaire HAL, est destinée au dépôt et à la diffusion de documents scientifiques de niveau recherche, publiés ou non, émanant des établissements d'enseignement et de recherche français ou étrangers, des laboratoires publics ou privés. 


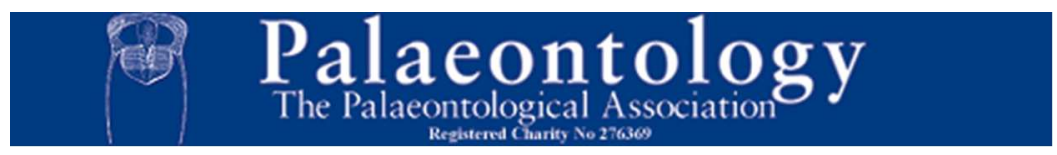

Tachyoryctes makooka (Tachyoryctini, Spalacidae, Rodentia) and its bearing on the phylogeny of the Tachyoryctini

\begin{tabular}{|r|l|}
\hline Journal: & Palaeontology \\
\hline Manuscript ID: & PALA-08-11-3217-OA.R1 \\
\hline Manuscript Type: & Original Article \\
\hline Date Submitted by the Author: & n/a \\
\hline Complete List of Authors: & $\begin{array}{l}\text { López Antoñanzas, Raquel; Museo Nacional de Ciencias Naturales-CSIC, } \\
\text { Paleobiology } \\
\text { Wesselman, Hank; SharedWisdom, }\end{array}$ \\
\hline Key words: & $\begin{array}{l}\text { Mammalia, Rhizomyinae, Systematics, Cladistics, Cenozoic, Africa, Zeit Wet } \\
\text { Phase }\end{array}$ \\
\hline
\end{tabular}




\title{
Tachyoryctes makooka (Tachyoryctini, Spalacidae, Rodentia) and its bearing on the phylogeny of the Tachyoryctini
}

\author{
Raquel López-Antoñanzas ${ }^{1}$ and Henry B. Wesselman ${ }^{2}$ \\ ${ }^{1}$ Departamento de Paleobiología, Museo Nacional de Ciencias Naturales-CSIC, c/ \\ José Gutiérrez Abascal 2, Madrid 28006, Spain \\ ${ }^{2}$ SharedWisdom, PO Box 369, Captain Cook, Hawaii 96704, USA \\ E-mails: ralopan@mncn.csic.es (RLA); hw@sharedwisdom.com (HW)
}

\begin{abstract}
The Rhizomyinae is a subfamily of myomorph rodents within the family Spalacidae. It is subdivided into two tribes: the Asian Rhizomyini and the Tachyoryctini. Even though the origin of the Tachyoryctini is to be found in Asia, they are nowadays restricted to Africa. African Tachyoryctini are known from the Late Miocene and include a single genus with five species: the recently discovered Tachyoryctes makooka, which is described in detail in this work, T. pliocaenicus, $T$. konjiti and the two extant T. splendens and T. macrocephalus. Their closest Asian counterparts are the Late Miocene Protachyoryctes and Eicooryctes. A cladistic analysis involving all the above-mentioned taxa was carried out. Protachyoryctes tatroti turned out to be the most basal species of the ingroup followed by the Ethiopian Tachyoryctes makooka. Both taxa show some primitive traits like the protosinus on the first upper molars, short but distinct mesolophids on the lower molars and the presence of the mure on the cheek teeth. T. pliocaenicus and the most derived Tachyoryctini share the synapomorphic reduction or loss of these characters. The increase in hypsodonty
\end{abstract}


evidenced in this lineage is correlated with the transition from a humid to a drier climate that started at the beginning of the Pliocene.

Keywords: Mammalia; Rhizomyinae; Systematics; Cladistics; Cenozoic; Africa, Zeit Wet Phase. 


\section{INTRODUCTION}

The Rhizomyinae are a subfamily of myomorph rodents belonging to the family Spalacidae.

McKenna and Bell (1997) subdivided this group into two tribes: the Rhizomyini Winge, 1887 and the Tachyoryctini (Miller and Gidley, 1918)McKenna and Bell, 1997. These tribes are equivalent to the subfamilies Rhizomyinae (Winge, 1887) Thomas, 1897 and Tachyoryctinae Miller and Gidley, 1918 as diagnosed by Flynn (1982a) and retained by Musser and Carleton (2005). Extant rhizomyines are fossorial rodents that live in southern Asia and eastern Africa. The Asian forms or "bamboo rats" include two genera (Rhizomys and Cannomys). There is only one living African genus, Tachyoryctes, the "mole rat", whose number of species is uncertain, but possibly only two: T. splendens and T. macrocephalus (Misonne 1971:7). Although Rhizomyinae are today moderately diversified, this taxon has had a flourishing history, as reflected by the

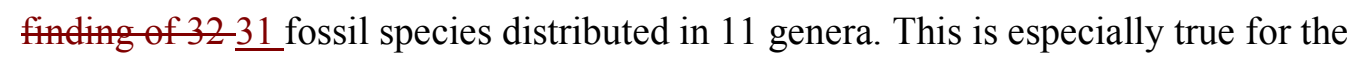
Asian continent, from where most of the taxa come (Pakistan, Afghanistan, India, Thailand and China). In contrast, the African rhizemyines-fossil record, known as far back as the Early Miocene, is much poorer, being only represented by four genera: Prokanisamys, Pronakalimys, Nakalimys and Tachyoryctes. Fossil representatives of the latter genus are restricted to Ethiopia. Until recently the most ancient record of Tachyoryctes dated from the Pliocene and only two fossil species of this genus were known: T. pliocaenicus and T. konjiti (Sabatier 1978, 1979, 1982). The discovery in 2009 of a new species, T. makooka, from various Late Miocene and Pliocene localities from the Middle Awash (Ethiopia) pushed back the existence of this genus to Late Miocene times (Wesselmann et al. 2009). Until this finding, there had been a gap 
between Protachyoryctes tatroti and Eicooryctes kaulialensis from the Late Miocene of Pakistan and the derived African Tachyorictini. Wesselmann et al.'s (2009) work dealt with the study of the whole micromammal fauna from the Middle Awash, and, therefore, included only a preliminary description of the available material of Tachyoryctes makooka and no detailed comparisons with the closest fossil species. The aim of the present work is to offer a detailed account. The comparisons will be made with the most derived Asian and African Tachyoryctinae (sensu Flynn, 1990), which are the species belonging to the genera Protachyoryctes, Eicooryctes and Tachyoryctes. Finally, a premier cladistic analysis of the intrarelationships of the species currently ascribed to these genera will be performed in order to assess the phylogenetical position of T. makooka, the most ancient species of Tachyoryctes known to date.

\section{MATERIAL AND METHODS}

The study presented below is based on the examination of original specimens, casts and data from the literature. We examined the following: skulls of extant Tachyoryctes macrocephalus (ZMB 36656, ZMB 55165, ZMB 36649 in the MB and C.G. 1972-73, C.G. $1972-74$, C.G. $1972-75$, C.G. 1972-76, C.G. $1974-202$ in the MNHN), T. splendens (ZMB 12, ZMB 78, ZMB 79, ZMB 80, ZMB 81, ZMB 83, ZMB 88, ZMB 114, ZMB 117, ZMB 3404, ZMB 3403, ZMB 9015, ZMB 16048, ZMB 28069, ZMB 36601-13, ZMB 36618, ZMB 36620-36621, ZMB 36624-36634, ZMB 36636-36637, ZMB 36640-36646, ZMB 36648, ZMB 36650-36655, ZMB 46257, ZMB 48300, ZMB 72559-72593, ZMB 7721 in the MB and C.G. 1993-217, C.G. 1993-231, C.G. 1993220, C.G. 1993-238, C.G. 1933-2752, C.G. 2000-685, C.G. 1961-33, C.G. 1972-10, C.G. 1972-27, C.G. 1972-39, C.G. 1972-51, C.G. 1972-64, C.G. 1972-65, C.G. 1972- 
68, C.G. 1993-222, C.G. 1993-225, C.G. 1993-241, C.G. 1993-246, C.G. 1993-250, C.G. 1993-253, C.G. 1993-254, C.G. 1993-257, C.G. 1993-263, C.G. 1993-265, C.G. 1993-268, C.G. 1993-272, C.G. 1993-274, C.G. 1993-289, C.G. 1993-302, C.G. 1993303, C.G. 1993-308, C.G. 1993-323, C.G. 1933-2746, C.G. 1933-2756, C.G. 1905-385, C.G. 1933-2745, C.G. 1933-2748, C.G. 1960-454, C.G. 1962-2292, C.G. 1970-210, C.G. 1972-16, C.G. 1972-19, C.G. 1972-44, C.G. 1972-46, C.G. 1972-50, C.G. $1972-$ 54, C.G. 1972-58, C.G. 1993-221, C.G. 1993-223, C.G. 1993-232, C.G. 1993-238, C.G. 1993-245, C.G. 1993-281, C.G. 1993-288, C.G. 1993-294, C.G. 1993-304, C.G. $1993-$ 307, C.G. 1993-318, C.G. 1993-322, C.G. 1960-453, C.G. 1962-2290, C.G. 1972-14, C.G. 1972-25, C.G. 1972-29, C.G. 1972-41, C.G. 1972-57, C.G. 1974-202, C.G. 1991629, C.G. 1993-217, C.G. 1993-224, C.G. 1993-239, C.G. 1993-240, C.G. 1993-249, C.G. 1993-261, C.G. 1993-270, C.G. 1993-292b, C.G. 1993-295, C.G. 1993-296, C.G. 1993-316, C.G. 1961-921, C.G. 1972-11, C.G. 1972-15, C.G. 1972-17, C.G. 1972-24, C.G. 1972-33, C.G. 1972-37, C.G. 1972-45, C.G. 1972-52, C.G. 1972-53, C.G. 197269, C.G. 1981-533, C.G. 1988-119, C.G. 1993-226, C.G. 1993-227, C.G. 1993-228, C.G. 1993-230, C.G. 1993-235, C.G. 1993-237, C.G. 1993-242, C.G. 1993-247, C.G. 1993-259, C.G. 1993-260, C.G. 1993-267, C.G. 1993-283, C.G. 1993-284, C.G. $1993-$ 286, C.G. 1993-287, C.G. 1993-309, C.G. 1993-310, C.G. 1993-315, C.G. 1993-317, C.G. 1993-320, C.G. 1933-2747, C.G. 1972-06, C.G. 1972-21, C.G. 1972-26, C.G. 1972-30, C.G. 1972-34, C.G. 1972-43, C.G. 1972-59, C.G. 1972-62, C.G. 1972-66, C.G. 1972-67, C.G. 1993-231, C.G. 1993-234, C.G. 1993-236, C.G. 1993-256, C.G. 1993-275, C.G. 1993-278, C.G. 1993-285, C.G. 1993-290, C.G. 1993-291, C.G. $1993-$ 300, C.G. 1993-305, C.G. 1993-314, C.G. 1962-2291, C.G. 1972-09, C.G. 1972-12, C.G. 1972-31, C.G. 1972-35, C.G. 1972-40, C.G. 1972-47, C.G. 1972-61, C.G. 1988242, C.G. 1993-219, C.G. 1993-220, C.G. 1993-248, C.G. 1993-251, C.G. 1993-258, 
C.G. 1993-262, C.G. 1993-273, C.G. 1993-276, C.G. 1993-282, C.G. 1993-299, C.G. 1993-313, C.G. 1993-321, C.G. 1933-2749, C.G. 1972-18, C.G. 1972-20, C.G. 197223, C.G. 1972-42, C.G. 1972-48, C.G. 1972-55, C.G. 1972-56, C.G. 1972-71, C.G. 1993-218, C.G. 1993-229, C.G. 1993-243, C.G. 1993-264, C.G. 1993-269, C.G. 1993271, C.G. 1993-277, C.G. 1993-279, C.G. 1993-292, C.G. 1993-297, C.G. 1993-298, C.G. 1993-306, C.G. 1993-311, C.G. 1993-319, C.G. 1993-324, C.G. 1972-07, C.G. 1972-08, C.G. 1972-13, C.G. 1972-22, C.G. 1972-28, C.G. 1972-32, C.G. 1972-36, C.G. 1972-38, C.G. 1972-49, C.G. 1972-60, C.G. 1972-63, C.G. 1972-70, C.G. 1993233, C.G. 1993-244, C.G. 1993-252, C.G. 1993-255, C.G. 1993-266, C.G. 1993-280, C.G. 1993-293, C.G. 1993-301, C.G. 1993-312, C.G. 1933-2752, in the MNHN), isolated teeth, maxillary fragments and mandible fragments of the following extinct species: Tachyoryctes makooka (KUS-VP-1/2, DID-VP-1/16, AMW-VP-1/29, KUSVP-1/31, AME-VP-1/51, AMW-VP-1/59, AME-VP-1/75, AMW-VP-1/82, AME-VP1/94, AME-VP-1/97, AMW-VP-1/99, DID-VP-1/103, AMW-VP-1/111, AMW-VP1/115, AMW-VP-1/116, ALA-VP-2/64, ALA-VP-2/65, STD-VP-2/94, ALA-VP-2/170, ALA-VP-2/173, ALA-VP-2/174, ALA-VP-2/175, ALA-VP-2/177, ALA-VP-2/185, ALA-VP-2/321, STD-VP-2/862, STD-VP-2/903, STD-VP-2/908, ASK-VP-3/172, ASK-VP-3/173, ASK-VP-3/254, ASK-VP-3/256, ASK-VP-3/257, ASK-VP-3/258, ASK-VP-3/260, ASK-VP-3/261, ASK-VP-3/263, ASK-VP-3/265, ASK-VP-3/266, ASK-VP-3/269, ASK-VP-3/270, ASK-VP-3/271, ASK-VP-3/276, ASK-VP-3/277, ASK-VP-3/279, ASK-VP-3/284, ASK-VP-3/287, ASK-VP-3/288, ASK-VP-3/291, ASK-VP-3/292, ASK-VP-3/293, ASK-VP-3/294, ASK-VP-3/295, ASK-VP-3/296, ASK-VP-3/297, ASK-VP-3/298, ASK-VP-3/303 in the NME), Rhizomyides sivalensis (casts of D97, D275 and BM (NH) 15926 in the BSP) and Protachyoryctes tatroti (cast of GSI-D272 in the BSP and AMNH). 
First, second, and third lower molars are designated as $\mathrm{m} 1, \mathrm{~m} 2$ and $\mathrm{m} 3$, and first, second, and third upper molars as M1, M2 and M3, respectively. The terminology used in the tooth descriptions follows the rodent dental terminology of Flynn (1982) with some adjustments (Text-figure $1 \mathrm{~A}-\mathrm{D})$.

The cladistic analysis involves all species of the genus Tachyoryctes (extant and fossil) as well as those of the extinct genus Protachyoryctes and Eicooryctes.

Rhizomyides, which is a basal Tachyoryctinae according to the phylogenetic analysis of Flynn (1990), was selected as outgroup. The data matrix was built under Mesquite 2.6 (Maddison and Maddison 2009) and the analysis was run in TNT (Goloboff et al. 2008). Branch support was estimated through two complementary indices: Bremer Support (Bremer 1994) and Relative Bremer Support (Goloboff and Farris 2001). Abbreviations. ALA/VP, Alayla Vertebrate Locality 2, Middle Awash, Ethiopia; AMEVP, Amba East Vertebrate Locality, Middle Awash, Ethiopia; AMNH, American Museum of Natural History, New York; AMW-VP, Amba West Vertebrate Locality, Middle Awash, Ethiopia; ASK-VP, Asa Koma Vertebrate Locality, Middle Awash, Ethiopia; BSP, Bayerische Staatssammlung für Paläontologie und Historische Geologie, Munich, Germany; C.G, Catalogue general du Laboratoire des Mammifères et Oiseaux du MNHN, Paris, France; DID-VP, Digiba Dora Vertebrate Locality, Middle Awash, Ethiopia; GAW-VP, Gawto Vertebrate Localities, Middle Awash, Ethiopia; KUS-VP, Kuseralee Vertebrate Locality, Middle Awash, Ethiopia; MNHN, Muséum national d'Histoire naturelle, Paris, France; NME, National Museum of Ethiopia, Addis Ababa, Ethiopia; NHM, Natural History Museum, London, England; PMAE, Peabody Museum of Archaeology and Ethnology, Cambridge, USA; PMNH, Pakistan Museum of Natural History, Islamabad, Pakistan; STD-VP, Saitune Dora Vertebrate Locality, Middle 
Awash, Ethiopia; WKH-VP, Worku Hassan Vertebrate Locality, Middle Awash, Ethiopia; ZMB, Zoologische Sammlung, Museum für Naturkunde der HumboldtUniversität, Berlin, Germany.

\section{SYSTEMATICS}

\section{Family SPALACIDAE Gray, 1821} Subfamily RHIZOMYINAE Winge, 1887

\section{Tribe TACHYORYCTINI Miller and Gidley, 1918}

\section{Genus TACHYORYCTES Rüppell, 1836}

Type species. Tachyoryctes splendens (Rüppell, 1836).

Referred species. Tachyoryctes splendens, Tachyoryctes macrocephalus, Tachyoryctes konjiti, Tachyoryctes pliocaenicus, Tachyoryctes makooka.

Tachyoryctes makooka Wesselman, Black and Asnake, 2009

Text-figs 2A-M, 3A-L; see also Wesselman et al. 2009

Holotype. DID-VP-1/16, left mandible fragment with m1-m3 (Text-fig. 1A).

Measurements. Measurements of upper and lower teeth are given in Wesselman et al. (2009:129).

Type locality. Digiba Dora Vertebrate Locality 1, Middle Awash, Ethiopia.

Age. Late Miocene (5.7 Ma). 
Other localities. ALA-VP-2, AME-VP-1, AMW-VP-1, ASK-VP-3, GAW-VP-1, GAWVP-3, KUS-VP-1, STD-VP-2, WKH-VP-1.

Age range. Late Miocene-Early Pliocene (5.7-4.85 Ma).

Emended diagnosis. Hypsodont (H M2 $\approx \underline{\underline{\mathrm{mm}}}$ ) and lophodont cheek teeth with nearly flat occlusal surfaces, constricted mures; upper molars with long mesolophs; M1 with distinct protosinus; mandible with nearly horizontal masseteric crest; lower molars with mesolophids usually short and distinct or appressed to the hypolophid; $\mathrm{m} 1$ with a posterior metaconid-protoconid connection and distinct anterolabial sinusid; m3 elongated.

Differential diagnosis. Tachyoryctes makooka differs from Protachyoryctes tatroøti in having a posterior metaconid-protoconid connection on the $\mathrm{m} 1$, in lacking a bilobed anteroloph on the M1 and in having short mures on the upper and lower molars. It differs from Eicooryctes kaulialensis, Tachyoryctes pliocaenicus, T. splendens and T. macrocephalus in having an anterolingual flexus on the M1. T. makooka is distinct from E. kaulialensis in having an elongated m3. T. makooka differs from T. pliocaenicus, T. splendens and T. macrocephalus in having short but distinct mure on the cheek teeth and the mesolophids more developed.

Description.

Upper dentition 
M1. These teeth are larger than the M2 and M3. The M1 has four transverse lophs (anteroloph, protoloph, mesoloph and metaloph-posteroloph), all of which join at the margin of the tooth, isolating three buccal enamel lakes. The posterior enamel lake is elongated and much larger than the other two. The M1 has a weak, but distinct, protosinus, and a deep lingual sinus directed anteriorly toward the first of the three buccal enamel lakes. In advanced early wear, the sinus joins the first enamel lake (they are nearly confluent in ALA-VP-2/321, see Text-fig. 3A). The protocone is a posteriorly directed bent loph. The hypocone has a strong oblique anterior arm and a narrower transverse posterior one. The anteroloph is not bilobed. The broad protoloph is anterobuccally directed. The mesoloph is long and straight; it is connected to the anterior arm of the hypocone. At the state of wear of all recorded M1, the metaloph is fused with the posteroloph. It is unknown if at an earlier state of wear these structures would be distinct. All M1 have a short mure and are three rooted (two labial and a lingual that is the-heaviest one).

M2. The M2 resembles the M1, but with the occlusal outline more rounded and without protosinus. The dental pattern of the M2 shows the same four lophs delimiting three buccal enamel lakes, of which the posterior one is the largest. The lingual sinus is also deep and directed anteriorly toward the first of the three buccal enamel lakes, with which it confluxes_joins in an advanced state of early wear (e.g., ASK-VP-3/265, Textfig. $3 \mathrm{H})$. The mesoloph is narrow and straight. These teeth have the mure constricted and are four rooted.

M3. The occlusal outline of this tooth is rounded with its posterior part narrower than the anterior one. It has the same four lophs as the M1 and M2, although the posteroloph 
is the shortest one. The lingual sinus is confluent with the anterior labial enamel lake forming a narrow and elongated central reentrant that divides the tooth into two parts. The anteroloph is a long continuation of the protocone. The protoloph and narrow mesoloph extend from the anterior and posterior ends of the broad anterior arm of the hypocone respectively. The metaloph does not join with the hypocone but with the lingual end of the posteroloph. This latter is a short continuation of the posterior arm of the hypocone. These teeth are three rooted.

Mandible. The dentary is slender and relatively shallow. The mental foramen is situated anterior to the $\mathrm{m} 1$ and at the level of the lower masseteric crest. This latter is nearly horizontal. The temporalis fossa is narrow and shallow. The lower incisors are relatively small and with gently rounded enamel.

\section{Lower dentition}

$m 1$. The occlusal outline of the tooth is oval, narrower anteriorly. They have four main lophids (anterolophid, metaconid-metalophid, entoconid-hypolophid and posterolophid) and a short, but usually distinct, mesolophid. All the specimens show a posterior metaconid-protoconid connection. A well-developed anterolophulid connects the Vshaped protoconid with the anterolophid. In early wear, the metaconid joins lingually the anterolophid, isolating a small, circular, anterior enamel lake. At this stage of wear neither the metalophid nor the hypolophid join at the margin of the tooth and, therefore, the mesosinusid and the posterosinusid remain open (e.g., ALA-VP-2/177, ASK-VP3/257, ASK-VP-3/287, see Text-fig. 2A-C). In advanced wear, these lingual reentrants are close off, isolating enamel lakes (e.g., AMW-VP-1/111, AMW-VP-1/115, AMW- 
VP-1/116, Text-fig. 2K, M). The anterolabial sinusid is shallow but very distinct. In advanced wear, the labial anterolophid connects to the protoconid enclosing a minute shallow enamel lake (e.g., DID-VP-1/16, Text-fig. 1A), which disappears with further wear (e.g., AMW-VP-1/116, Text-fig. 2M). The labial sinusid is rather shallow and terminates high above the base of the enamel. The mesolophid extends from the long, broad and oblique posterior arm of the protoconid; it is short and close to the hypolophid, being distinct in early wear (e.g., ALA/VP-2-177, ASK-VP-3/257, ASKVP-3/277, ASK-VP-3/287, ASK-VP-3/294, see Text-figs 2A-D). Through wear, the lingual end of the mesolophid joins the hypolophid enclosing a small and shallow enamel lake (e.g., DID-VP-1/16, AME-VP-1/94, AME-VP-1/97, AMW-VP-1/99, Textfigs 1A, 2L). In late wear, this enamel lake disappears: the mesolophid is completely fused with the hypolophid (e.g., AMW-VP-1/111, AMW-VP-1/115, AMW-VP-1/116, Text-fig. 2K, M). The posterolophid is a long continuation of the bent hypoconid. These teeth have two roots.

$m 2$. The occlusal outline of this tooth is almost square with the posterior part slightly narrower than the anterior one. They have three main lophids (anterolophid-metalophid, hypolophid and posterolophid). After moderate wear, the lophids join at the margin of the tooth isolating two transversely elongated enamel lakes, of which the anterior one is being the largestlarger. In early wear, the anterolophid is fused with the metalophid forming a unique loph that is a long continuation of the short and transversal anterior arm of the protoconid. The protoconid is $\mathrm{V}$-shaped; its posterior arm is broad and oblique. The hypolophid is strong and directed lingually from the mure. The mesolophid is usually appressed to the hypolophid (e.g., ASK-VP-3/291, ASK-VP3/294, Text-fig. 2E). In some specimens (AMW-VP-1/99, AME-VP-1/94, AME-VP- 
1/97, see Text-fig. 2J, L), it connects with the hypolophid, enclosing a small and shallow enamel lake. After moderate wear, it is completely fused with the hypolophid (e.g., DID-VP-1/103, Text-fig. 2F). The labial sinusid is deep and directed posterolingually. These teeth have the a short mure short and they are three rooted.

$m 3$. It is oval in occlusal outline with the posterior side rounded and slightly narrower than the anterior one. These teeth resemble the $\mathrm{m} 2$, but they are more elongated (longer) than them. They have the same three main lophids, which join at the margin of the tooth with moderate wear, isolating two transversely elongated enamel lakes (the posterior one smaller than the anterior one). After moderate wear the anterolophid, which expands from the anterior arm of the protoconid, fuses with the metalophid. In early wear (e.g., ASK-VP-3/270, STD-VP-2/903, Text-fig. 2H-I), anterolophid and metalophid are differentiated and enclose a tiny and shallow anterior enamel lake. At this stage of wear the lingual sinusids are still open. The labial sinusid is posterolingually directed and deep. The protoconid is V-shaped with a short and transverse anterior arm and an oblique and broad posterior one, from which the short mesolophid expands (e.g., ASK-VP-3/270, ASK-VP-3/263). After moderate wear, the mesolophid is completely fused with the hypolophid (ASK-VP-3/273, AMW-VP-1/99, Text-fig. 2L). These teeth are two rooted.

\section{Comparisons}

Protachyoryctes tatroti Hinton, 1933. This species was named by Hinton (1933) on the basis of a partial right mandible with m1-m3, which is housed in the paleontological collections of the NHM. Hinton (1933) indicated that this material comes from an 
earliest Pleistocene horizon near Tatrot village (Salt Range, Pakistan). However, its provenance has been thrown into doubt since, in particular, the discovery of new material belonging to this taxon from the Late Miocene (6.9-6.5 Ma) localities Y434 and Y369 in the Dhok Pathan Formation of the Potwar Plateau (Pakistan) (Flynn 1982a). Flynn (1982a) pointed out the presence directly beneath Tatrot of much older rocks (more than $6 \mathrm{Ma}$ ), from which he suspected the holotype of $P$. tatroti could come. We share these doubts in view of the great resemblance between this species and the Late Miocene Tachyoryctes makooka.

Even though the morphology of the teeth of $P$. tatroti soundly recalls that of $T$. makooka and their size is comparable, there are some differences between both the taxa. One of the more remarkable concerns the connection between the metaconid and the protoconid on the $\mathrm{ml}$, which is posterior in T. makooka, whereas it is anterior in $P$. tatroti. In addition, the labial sinusid (especially on the $\mathrm{m} 2$ and $\mathrm{m} 3$ ) is deeper in the former species. With regard to the upper molars, the M1 of $P$. tatroti shows a feeble bilobation on the anteroloph that is completely absent in T. makooka. The cheek teeth of T. makooka are more hypsodont and have the mure more constricted than those of $P$. tatroti.

Eicooryctes kaulialensis Flynn, 1982. Flynn (1982a) named this taxon on the basis of some palate and dentary fragments from the Late Miocene (6.9-6.4 Ma) localities Y434, Y437 and Y438 of the upper Dhok Pathan Formation, Kaulial Kas, Potwar Plateau, Pakistan. Its holotype, a palate and snout with broken incisors and left and right M1-M2 (YGSP 15320), is currently housed at the PMAE and it should eventually be returned to Pakistan and would be deposited at the PMNH. Unfortunately, no additional material of this species has been found to date. 
The teeth of Eicooryctes kaulialensis are smaller than those of Tachyoryctes makooka and, even if there are-close in morphology, they show some differences. For instance, the M1 of T. makooka have a weak, but distinct, protosinus on the M1 that is lacking in E. kaulialensis. Furthermore, the $\mathrm{m} 3$ of the former species are elongated, whereas those of E. kaulialensis are short.

Tachyoryctes pliocaenicus Sabatier, 1978. This species was named on the basis of eight mandibles (some of them incomplete) and a fragmentary skull with right and left M1M2 from the Pliocene Hadar Formation, Ethiopia (Sabatier 1978). The holotype, a right mandible with m1-m3 (AL.288.29), is housed in the NME.

The cheek teeth of Tachyoryctes pliocaenicus are smaller than those of T. makooka. From a morphological point of view, these taxa also present some significant differences. With regard to the upper molars, those of $T$. pliocaenicus lack the mure and have a very long sinus that isolates the anterior part of the teeth from the posterior enepart. In contrast, the mure is constricted, but present, and the sinus long, but to a much lesser extent, in T. makooka. The M1 of T. pliocaenicus lack the protosinus that can be observed in those of T. makooka. With respect to the lower molars, the lobes are more oblique, the mure more constricted (or even lacking) and the mesolophids less developed in T. pliocaenicus than in T. makooka. In addition, the anterolabial sinusid of the $\mathrm{m} 1$ is shallower in T. pliocaenicus and the posterior side of the $\mathrm{m} 3$ is more reduced in T. pliocaenicus than in T. makooka.

Tachyoryctes konjiti Sabatier, 19791982 . This taxon was named by Sabatier (19791982) on the basis of a hundred of isolated molars from the Pleistocene locality of Garba VIII (Melka Kunturé, Ethiopia). Its holotype (Garba VIII B 16), an isolated M1, 
is housed in the NME. Additional material of T. konjiti has been found in other Pleistocene Ethiopian localities such as Garba IV, Gombore I $\gamma$, Simbiro, Gombore II B/C, Garba III E, Garba X and Garba VIIIB (Sabatier 1979, 1982; Galloti et al. 2010). The cheek teeth of T. konjiti are somewhat smaller than those of T. makooka. The molars of the former species are hypselodont, whereas those of T. makooka are rooted. As in the case of $T$. pliocaenicus, the upper molars of $T$. konjiti lack the mure and they have a very long sinus that divides the tooth into two parts. In contrast, the M1 and M2 of T. makooka have a short, but distinct, mure and the sinus is not as long as in $T$. konjiti. In addition, the M3 of the latter species is much more elongated than that of $T$. makooka. With regard to the lower molars, in those of $T$. konjiti the mesolophids are completely fused with the hypolophids, whereas they are mostly short and distinct or appressed to the hypolophid in T. makooka. The connection of the metaconid with the protoconid is anterior on the $\mathrm{m} 1$ of $T$. konjiti, whereas it is posterior in T. makooka. Furthermore, the $\mathrm{m} 2$ and $\mathrm{m} 3$ of the former species lack the mure and the long sinusid separates the anterior and posterior parts of the teeth. In contrast, on the $\mathrm{m} 2$ and $\mathrm{m} 3$ of T. konjiti the sinus is long, but it does not divide the teeth and the mures are present.

Tachyoryctes splendens (Rüpell, 1836). In 1836, Rüpell named a new species of rodent that he discovered in Ethiopia. In his work he pointed out that this rodent resembled very much togreatly Bathyergus from Cape of Good Hope in the skull, crown and size of the teeth, toes and claws. However, he also noticed some singularities in the Ethiopian animal like the small size of its ear pinna and its longer and more rounded tail. Since very few species of the genus Bathyergus were known at that time, he refrained himselffrom naming a new genus, even though eminent Londoner and Parisian experts thought otherwise. Should it turn out in the future that the latterlater 
scientists wanted to transfer this species into a new genus, he suggested using the genus name Tachyoryctes in a footnote (Rüppell 1836: 35).

Tachyoryctes splendens is smaller than T. makooka. In addition, there exist various morphological differences between them. The cheek teeth of $T$. splendens are hypselodont and not rooted as those of T. makooka. The second and third upper and lower molars of $T$. splendens lack the mure, whereas it is present in all but the third upper molar in T. makooka. Concerning the upper molars, the first and second molars of T. makooka have the sinus much shorter than those of T. splendens. The M2 of this latter species has a sinus so long sinus-that isolates the anterior part of the teeth from the posterior one. The M1 of $T$. splendens lacks the protosinus, whereas it is distinct in $T$. makooka. The M3 of T. splendens is elongated, much longer than in T. makooka. The lower molars of $T$. splendens lack the mesolophids that are completely fused with the hypolophid. In T. makooka, the mesolophids are usually distinct. The metaconid on the $\mathrm{m} 1$ of $T$. splendens connects anteriorly with the protoconid, whereas this connection is posterior in T. makooka. The mure is lacking on the $\mathrm{m} 2$ and $\mathrm{m} 3$ of $T$. splendens but distinct in T. makooka. The sinusid is shorter in the latter species than in the former, in which the anterior part of the $\mathrm{m} 2$ and $\mathrm{m} 3$ is isolated from the posterior one, unlike. This is not the case in T. makooka.

Tachyoryctes macrocephalus (Rüppell, 1842). In 1842, Rüppell named the new species Rhizomys macrocephalus on the basis of a rodent from Shoah province (southern Ethiopia) that was sent to him (Rüppell 1842).

The morphology of the cheek teeth of T. macrocephalus is similar to that seen in $T$. splendens. The difference between these taxa rests in the size. Therefore, the differences 
observed between $T$. splendens and $T$. makooka apply also to differentiate $T$. macrocephalus from the latter.

\section{DISCUSSION}

Fossils of African rhizomyines are scarce. The oldest and sole evidence in the Lower Early Miocene (Fejfar and Horáček 2006; Wessels et al. 2003, 2008) is Prokanisamys sp. from Jebel Zelten (Libya). In this continent, a single species of rhizomyine is known from the Middle Miocene: Pronakalimys andrewsi from Fort Ternan (Kenya) (Tong and Jaeger 1993), two from the Upper Miocene: Nakalimys lavocati from Nakali (Kenya) (Flynn and Sabatier 1984) and the recently discovered and-subject of this work Tachyoryctes makooka from the Middle Awash (Ethiopia) (Wesselmann et al. 2009). From Pliocene localities of the Hadar Formation (Afar, Ethiopia), a single species of Tachyoryctes is known: T. pliocenicus (Sabatier 1978, 1979). Finally, the most recent fossil species of Tachyoryctes known to date is T. konjiti, which comes from various Pleistocene localities of Melka-Kunturé (Ethiopia) (Sabatier 1979,1982; Galloti et al. 2010).

As fossil rhizomyines are much more diverse in the Siwalik sequence of Southwest Asia, most of our knowledge concerning the evolution of this subfamily is due to the study of specimens recovered from this region (Black 1972; Jacobs 1978; Flynn 1982a, 1982b, 1983, 1985). From a morphological viewpoint, the African members of this clade do not appear far from the Asian ones, but their phylogenetic interrelationships are actually unknown. This motivated us to provide a substantiated hypothesis of their mutual relationships based on cladistic methods. The taxa taken into consideration are the most derived within Tachyoryctinae (sensu Flynn 1990). This subclade involves all 
extinct and extant species of Tachyoryctes as well as Protachyoryctes and Eicooryctes. Rhizomyides sivalensis has been chosen as outgroup based on the analysis carried out by Flynn (1990). The data matrix (16 characters, see Supplementary File 1) has been processed with TNT (Goloboff et al. 2008) with the "traditional search" option (using TBR). Owing to the lack of a priori information, all characters were unordered and equally weighted (Fitch optimality criterion). A single most parsimonious tree was generated (tree length: 26, consistency index: 0.923, retention index: 0.941). The relative Bremer support index, which is the ratio between favorable and contradictory evidence (Goloboff and Farris 2001; Goloboff et al. 2003), for each node is 89. This means that the tree is very well supported. Topologically, the cladogram is asymmetrical (Text-Figure 4): Protachyoryctes tatroti, Tachyoryctes makooka, Eicooryctes kaulialensis, T. pliocaenicus, T. konjiti are successive terminal taxa leading to the clade (T. macrocephalus, T. splendens).

Protachyoryctes tatroti is the most plesiomorphic species of the ingroup followed by Tachyoryctes makooka. The latter taxon, together with Protachyoryctes, is characterized by the presence of a protosinus on the M1. This trait, which is distinctive of some primitive genera of the subfamily like Prokanisamys, Kanisamys, Pronakalimys, Nakalimys and Rhizomyides (see Flynn 1982a), becomes less marked in P. tatroti and T. makooka (in which the protosinus is shallow) and is completely lost in Eicooryctes as well as in more derived Tachyoryctini. A large posterosinusid on the $\mathrm{m} 3$, a primitive character, is present in the more plesiomorphic members of the present ingroup (P. tatroti, T. makooka and E. kaulialensis). However, there is a trend to reduce it (as in T. pliocaenicus) and to finally lose it (as in T. konjiti and more derived members of the ingroup) within the lineage. As seen above, T. makooka is characterized by a connection between the metaconid and the protoconid on the $\mathrm{m} 1$. This type of 
connection is plesiomorphic for the subfamily (Flynn 1982a) and shared by all taxa of the present ingroup except for the very young individuals of the extant $T$.

macrocephalus and T. splendens, in which the connection is established in early wear. In addition, the cheek teeth of T. makooka as well as those of $P$. tatroti and $E$. kaulialensis are rooted (plesiomorphic condition). This condition is lost in $T$. pliocaenicus and the more derived members of the ingroup, which share the synapomorphy of having hypselodont molars.

Tachyoryctes makooka, Protachyoryctes tatroti, Eicooryctes kaulialensis and T. pliocaenicus present constricted mures and short mesolophids appressed to the hypolophids on the lower molars. The most derived members of the ingroup (T. konjiti, T. macrocephalus and T. splendens) have lost the mures and the mesolophids; the latter are completely fused with the hypolophids. The constriction of the mures and the reduction and migration of the mesolophids towards the hypolophids is actually an evolutionary trend within the Rhizomyinae as a whole (Flynn 1982a). Primitive rhizomyines (e.g., Prokanisamys, Pronakalimys, Nakalimys, Kanisamys) have long mesolophids and well-developed mures.

Even though all the derived Tachyoryctini analysed in this work are hypsodont, the African representatives of this clade show an increase in hypsodonty through time. Thus, the Late Miocene Tachyoryctes makooka is less hypsodont than the Pliocene $T$. pliocaenicus, which is in turn less than the Pleistocene T. konjiti and so on. After the arid condition northeastern Africa went through during the Tortonian (10.8-7 Ma), the region became humid at the transition to the Messinian (7-5.3 Ma) (. This time is called the Zeit Wet Phase, (Griffin 2002). At about 5.8 Ma, when T. makooka lived, the Zeit Wet Phase intensified until the beginning of theEarly Pliocene (at about 4.6 Ma), when the aridity increased in this zone (Griffin 2002). The trend to increase-increasing the 
hypsodonty showed shown in the African Tachyoryctini may be associated with the end of the Zeit Wet Phase. Incidentally, Flynn (1982a, 1985, 1986) observed an increase in hypsodonty in the northern Pakistan Siwaliks Late Miocene species of Rhizomyini (Rhizomyinae sensu Flynn 1990). This has been tentatively correlated with a transition to a drier and more seasonal climate 9.2 Ma ago, which intensified 7.8 Ma ago as evidenced by changes in the floodplain deposition and vegetation (Barry et al. 2002).

This phylogenetic analysis of the most derived representatives of the Tachyoryctini suggests that some nomenclatural adjustments will prove necessary when a comprehensive cladogram of this subfamily is available (López-Antoñanzas et al. in prep.). The latter will include the species of Prokanisamys, Pronakalimys, Nakalimys, Kanisamys, Rhizomyides, Protachyoryctes, Eicooryctes, Anepsirhizomys, Miorhizomys, and of the three extant genera. It is probable that either Eicooryctes kaulialensis or Tachyoryctes makooka will have to be reallocated to another genus. There are two possible scenarios concerning the origin of the African Tachyoryctini. In fact, a form originating from southern Asia may have entered Africa and given rise to Tachyoryctes makooka and all other African Tachyoryctini. This would imply that the presence of Eicooryctes kaulialensis in Asia is due to a reverse dispersal. The alternative hypothesis $\underline{\text { would rest on two unidirectional dispersal events from southern Asia to Africa. The first }}$ one would have been at the origin of T. makooka, whereas the derivation of all other African Tachyoryctini (T. pliocaenicus and more derived species) would have come from an independent entering of this group in Africa. The results of the present partial analysis of rhyzomyine phylogeny do not allow deciding if the species of Tachyoryctini $\underline{\text { recorded in Africa have a unique or multiple origins. }}$ 


\section{CONCLUSION}

During the last decade, the fossil record of African Miocene micromammals has improved thanks to the efforts of palaeontologists and archaeologists. The recent discovery of Tachyoryctes makooka from the Late Miocene of the Middle Awash not only filled-fills the temporal gap between Asian and African Tachyoryctini, but it-also sheds light on the relationships between the African and Asian members of the tribe. $T$. makooka emerges as a quite primitive species of Tachyoryctini, being hardly more advanced than Protachyoryctes. The clade composed of Eicooryctes and more derived Tachyoryctini displays many derived characters. The evolutionary trends of the Protachyoryctes-Tachyoryctes lineage include the reduction and final tost-loss of the protosinus on the M1, of the posterosinusid on the $\mathrm{m} 3$ and of the mure of the cheek teeth. In addition, the reduced mesolophids migrate toward the hypolophids to which they first appress and with which they finally fused. The increase of the hypsodonty and last-loss of the roots of the cheek teeth of the most derived Tachyoryctini appear to be related to the aridification that took place in northeastern Africa in Pliocene times.

Acknowledgements. We sincerely thank C. Denys (Muséum National d'Histoire Naturelle, Paris) and F. Mayer and N. Lange (Museum für Naturkunde der HumboldtUniversität, Berlin), G. Rößner (Staatssamlung für Paläontologie und Geologie, Munich) P. Holdroy (University of California, Berkeley), J. Galkin, J. Meng and R. O’Leary (American Museum of Natural History, New York) for having made available the rhizomyine material under their care. $\underline{\text { P. Mein (Université Claude Bernard, Lyon I, }}$ Villeurbanne) and L. Flynn (Harvard University, Cambridge) enhanced this work through careful, critical reading. L.D. Brandy (Neuville sur Touques), H. de Bruijn 
(Utrecht University, Utrecht), L. Marivaux (Université Montpellier II, Montpellier) and

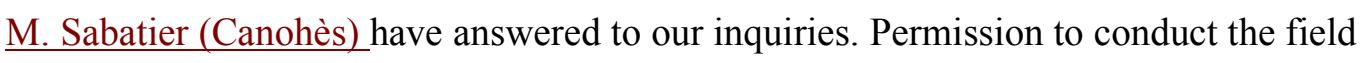
research in the Middle Awash carried out by HW and M. Asnake was granted by the Authority for Research and Conservation of Cultural Heritage, Ministry of Culture and Tourism, Ethiopia. We also thank the National Museum of Ethiopia (Addis Ababa) for the facilitation of field and laboratory studies. In addition, the Afar Regional Government and the Afar people of the Middle Awash region greatly facilitated and contributed to the successes of the geological and paleontological studies and discoveries of the Middle Awash research project. Gratitude is also expressed to T. White for his support of the microvertebrate studies conducted by HW, M. T. Black, and M. Asnake. The sojourn in Munich and Paris (RLA) were funded by the Alexander von Humboldt Foundation through sponsorships of renewed research stays in Germany and by the EDIT Gender Action Plan, respectively. This research received support from the SYNTHESYS Project (http://www.synthesys.info/), which is financed by European Community Research Infrastructure Action under the FP7 "Capacities" Program. RLA is currently supported by the Ramón y Cajal Program and the research project CGL2011-24829 of which she is PI.

\section{REFERENCES}

BARRY, J. C., MORGAN, M. E., FLYNN, L. J., PILBEAM, D., BEHRENSMEYER, A. K., MAHMOOD RAZA, S. KHAN, I. A., BADGLEY, C., HICKS, J. and KELLEY, J. 2002. Faunal and Environmental Change in the Late Miocene Siwaliks of Northern Pakistan Paleobiology, 28 (memoirs 3), 1-71.

BLACK, C. C. 1972. Review of fossil rodents from the Neogene Siwalik Beds of India and Pakistan. Palaeontology, 15, 238-266. 
BREMER, K. 1994. Branch support and tree stability. Cladistics, 10, 295-304.

FEJFAR, O. and HORÁČEK, I. 2006. The Early Miocene mammalian assemblages in Jebel Zelten, Libya. Lynx, 37, 95-105.

FLYNN, L. J. 1982a. Systematic revision of Siwalik Rhizomyidae (Rodentia). Geobios, $15,327-389$.

- 1982b. A revision of fossil rhizomyid rodents from northern India and their correlation to a rhizomyid biochronology of Pakistan. Geobios, 15, 583-588.

— 1985. Evolutionary patterns and rates in Siwalik Rhizomyidae (Rodentia). Acta Zoologica Fennica, 170, 141-144.

- 1983. Mosaic evolution in a family of fossorial rodents. 185-195. In BUFFETAUT, E., MAZIN, J. M. and SALMON, E. (eds). Actes du symposium paleontologique Georges Cuvier. Le Serpentaire, Montbeliard, 548 pp.

— 1986. Species longevity, stasis and stairsteps in rhizomyid rodents. Contributions to Geology University Wyoming, Special Papers, 3, 273-285.

- 1990. The natural history of rhizomyid rodents. 155-183. In NEVO, E. and REIG, O. A. (eds). Evolution of subterranean mammals at the organismal and molecular levels. Alan R. Liss. Inc, New York, 422 pp.

— and SABATIER, M. 1984. A Muroid Rodent of Asian affinity from the Miocene of Kenya. Journal of Vertebrate Paleontology, 3, 160-165.

GALlOTTI, R., COLLINA, C., RAYNAL, J. P., KIEFFER, G., GERAADS, D. and PIPERNO, M. 2010. The Early Middle Pleistocene Site of Gombore II (Melka Kunture, Upper Awash, Ethiopia) and the Issue of Acheulean Bifacial Shaping Strategies. African Archaeological Review, 27, 291-322.

GOLOBOFF, P. and FARRIS, J. 2001. Methods for quick consensus estimation. Cladistics, 17, 26-34. 
—, FARRIS, J. S., KÄLLERSJÖ, M., OXELMAN, B., RAMÍREZ, M. J. and SZUMIKA C. A. 2003. Improvements to resampling measures of group support. Cladistics, 19, 324-332.

—, FARRIS, J. and NIXON K. C. 2008. TNT, a free program for phylogenetic analysis. Cladistics, 24, 774-786.

GRIFFIN, D. L. 2002. Aridity and humidity: two aspects of the late Miocene climate of North Africa and the Mediterranean. Palaeogeography, Palaeoclimatology, Palaeoecology, 182, 65-91.

HINTON, M. A. C. 1933. Diagnoses of new genera and species of rodents from Indian Tertiary deposits. The Annals and Magazine of Natural History, 12, 620-622.

JACOBS, L. L. 1978. Fossil rodents (Rhizomyidae and Muridae) from Neogene Siwalik deposits, Pakistan. Museum of Northern Arizona Press Bulletin Series, 52, 103 pp.

MCKENNA, M. C. and BELL, S. K. 1997. Classification of Mammals above the Species level. Columbia University Press, New York, 631 pp.

MADDISON, W. P. and MADDISON, D. R. 2009. Mesquite: a modular system for evolutionary analysis, Version 2.6. Mesquite Project, Vancouver.

MILLER, G. S. and GIDLEY, J. W. 1918. Synopsis of the supergeneric groups of rodents. Journal of the Washington Academy of Science, 8, 431-448.

MISONNE, X. 1971. Order Rodentia. 1-39. In MEESTER, J.and SETZER, H. W. (eds). The Mammals of Africa: an identification manual. Smithsonian Institution Press, Washington.

MUSSER, G. G. and CARELTON, M. D. 2005. Superfamily Muroidea. 923-926. In Wilson, D. E. and Reeder, D. (eds). Mammal Species of the World, Vol. 2. Third edition. The John Hopkins University Press, Baltimore, 2142 pp. 
RÜPPELL, E. 1836. Neue Wirbelthiere, zu der Fauna von Abyssinien gehörig, entdeckt und beschrfieben. Part 7, 17-36. Frankfurt am Main. S. Schmerber.

— 1842. Säugethiere aus der Ordnung, der Nager, beobachtet im nordöstlichen Africa. Museum Senckenberg, 3, 99-116.

SABATIER, M. 1978. Un nouveau Tachyoryctes (Mammalia, Rodentia) du bassin Pliocene de Hadar (Ethiopie). Geobios, 11, 95-99.

— 1979. Les rongeurs des sites à hominides de Hadar et Melka-Kunture (Ethiopie). Unpublished Thèse de l'Université des Sciences et Techniques du Languedoc, Montpellier, $122 \mathrm{pp}$.

- 1982. Les rongeurs des sites pléistocènes de Melka-Kunturé, Ethiopie, Abbay $\mathbf{1 1}$, $\underline{45-64 .}$

TONG, H. and JAEGER, J. J. 1993. Muroid rodents from the Midle Miocene Fort Ternan locality (Kenya) and their contribution to the phylogeny of Muroids. Palaeontographica, Abteilung A, 229, 51-73.

THOMAS, O. 1897. On the genera of rodents: an attempt to bring up to date the current arrangement of the order. Proceedings of the general Meetings for scientific Business of the Zoological Society of London, 1896, 1012-1028.

WESSELS, W., FEJFAR, O., PELÁEZ-CAMPOMANES, P. and DE BRUIJN, H. 2003. Miocene small mammals from Jebel Zelten, Libya. Coloquios de Paleontología volumen extraordinario, 699-715. —, FEJFAR, O., PELÁEZ-CAMPOMANES, P., VAN DER MEULEN, A., DE BRUIJN, H. and EL-ARNAUTI, A. 2008. The age of the small mammal faunas from Jabal Zaltan, Libya. Garyounis Scientific Bulletin, 5, 129-138.

WESSELMAN, H. B., BLACK, M. T. and ASNAKE, M. 2009. Small Mammals. 105133. In Haile-Selassie, Y. and WoldeGabriel, G. (eds). Ardipithecus kadabba: Late 
1

2

3

4

5

6

7

8

9

10

11

12

13

14

15

16

17

18

19

20

21

22

23

24

25

26

27

28

29

30

31

32

33

34

35

36

37

38

39

40

41

42

43

44

45

46

47

48

49

50

51

52

53

54

55

56

57

58

59

60

Miocene Evidence from the Middle Awash, Ethiopia (The Middle Awash Series).

University of California Press, London, 664 pp.

WINGE, H. 1887. Jordfundne og nulevende gnavere (Rodentia) fra Lagoa Santa, Minas

Geraes, Brasilien. F. Dreyer, Kjøbenhavn, 178 pp. 


\section{Figure captions}

TEXT-FIG. 1. A-D. Dental terminology used in this paper (cheek teeth belonging to Tachyoryctes makooka). A, DID-VP-1/16 (holotype), left mandible with m1-m3. B, ASK-VP-3/269, right M1. C, STD-VP-2/94 left M2. D, ASK-VP-3/272, left M3. Scale bar equals $5 \mathrm{~mm}$.

TEXT-FIG. 2. A-M. Lower cheek teeth of Tachyoryctes makooka. A, ALA-VP-2/177, left m1. B, ASK-VP-3/257, left m1. C, ASK-VP-3/287, left m1. D, ASK-VP-3/277, right m1; E. ASK-VP-3/291, right m2; F. DID-VP-1/103, left m2; G. ALA-VP-2/65, left m2; H. STD-VP-2/903, right m3; I. ASK-VP-3/270, left m3; J. AME-VP-1/97, right mandible with m1-m3; K. AMW-VP-1/115, left mandible with m1-m3; L. AMW-VP1/99, left mandible with m1-m3; M. AMW-VP-1/116, left mandible with m1-m3. The scale bar equals $2 \mathrm{~mm}$, except for $\mathrm{J}-\mathrm{M}$ for which it is $5 \mathrm{~mm}$.

TEXT-FIG. 3. A-L. Upper cheek teeth of Tachyoryctes makooka. A, ALA-VP-2/321, right M1. B, ASK-VP-3/279, left M1. C, ASK-VP-3/297, right M1. D, ASK-VP-3/284, left M2. E, ASK-VP-3/296, left M1. F, ASK-VP-3/293, right M2. G, ASK-VP-3/260, right M2. H, ASK-VP-3/265, left. I, KUS-VP-1/31, right M2. J, ASK-VP-3/292, right m2. K, ALA-VP-2/174, left M2. L, ALA-VP-2/173, right M3. Scale bar equals $2 \mathrm{~mm}$.

TEXT-FIG. 4. Cladogram showing the relationships among the species of Protachyoryctes, Eicooryctes and Tachyoryctes and the phylogenetic position of Tachyoryctes makooka (matrix in Supplementary File 2). Bremer and Relative Bremer Indices are showed at the appropriate nodes. 
A-D. Dental terminology used in this paper (cheek teeth belonging to Tachyoryctes makooka). A, DID-VP1/16 (holotype), left mandible with m1-m3. B, ASK-VP-3/269, right M1. C, STD-VP-2/94 left M2. D, ASK-VP$3 / 272$, left M3. Scale bar equals $5 \mathrm{~mm}$. $81 \times 40 \mathrm{~mm}(300 \times 300 \mathrm{DPI})$ 
A-M. Lower cheek teeth of Tachyoryctes makooka. A, ALA-VP-2/177, left m1. B, ASK-VP-3/257, left m1. C, ASK-VP-3/287, left m1. D, ASK-VP-3/277, right m1; E. ASK-VP-3/291, right m2; F. DID-VP-1/103, left m2;

G. ALA-VP-2/65, left m2; H. STD-VP-2/903, right m3; I. ASK-VP-3/270, left m3; J. AME-VP-1/97, right mandible with m1-m3; K. AMW-VP-1/115, left mandible with m1-m3; L. AMW-VP-1/99, left mandible with m1-m3; M. AMW-VP-1/116, left mandible with m1-m3. The scale bar equals $2 \mathrm{~mm}$, except for J-M for which it is $5 \mathrm{~mm}$.

$200 \times 243 \mathrm{~mm}(300 \times 300$ DPI $)$ 


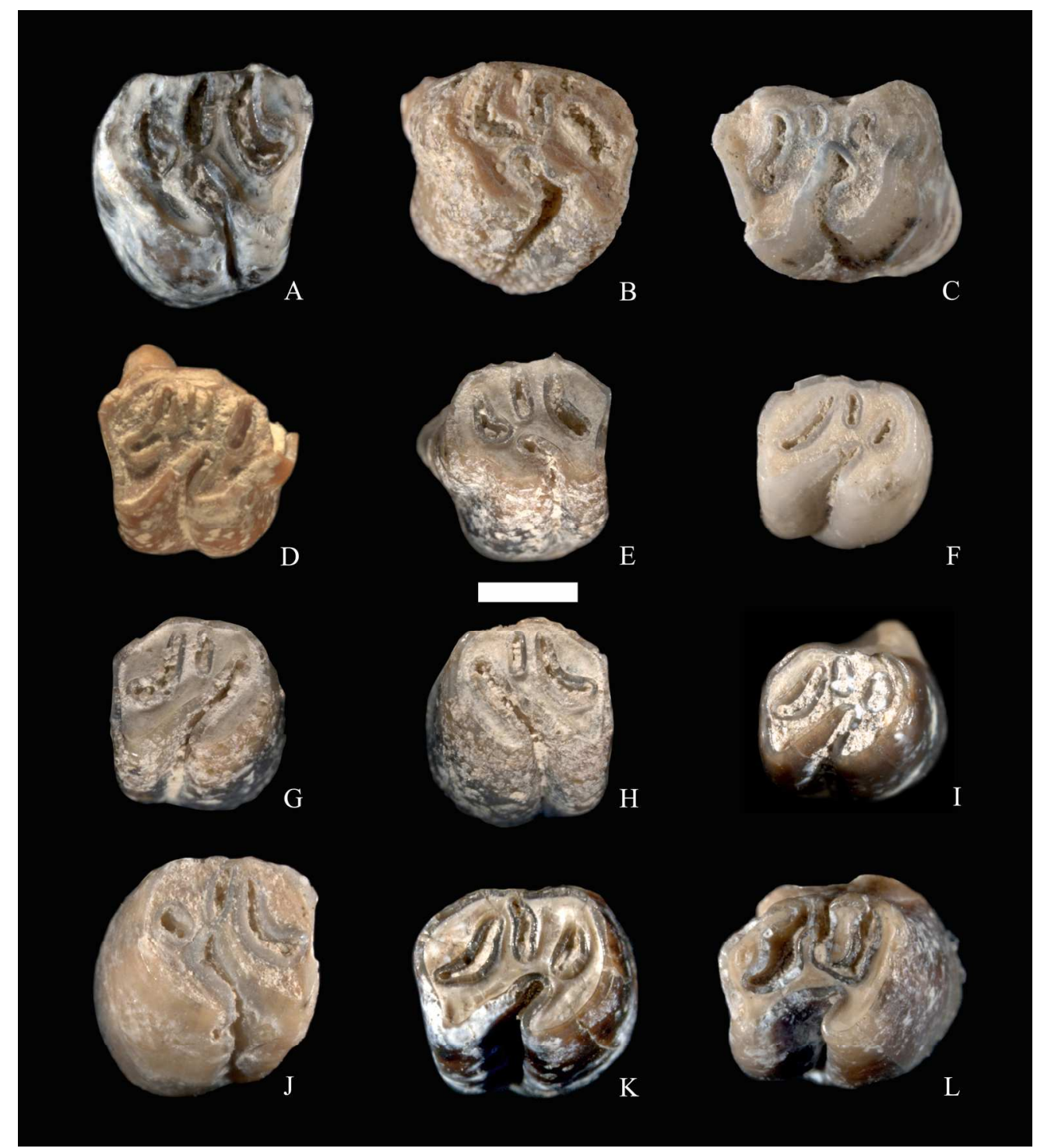

A-L. Upper cheek teeth of Tachyoryctes makooka. A, ALA-VP-2/321, right M1. B, ASK-VP-3/279, left M1. C, ASK-VP-3/297, right M1. D, ASK-VP-3/284, left M2. E, ASK-VP-3/296, left M1. F, ASK-VP-3/293, right M2. G, ASK-VP-3/260, right M2. H, ASK-VP-3/265, left. I, KUS-VP-1/31, right M2. J, ASK-VP-3/292, right m2. K, ALA-VP-2/174, left M2. L, ALA-VP-2/173, right M3. Scale bar equals $2 \mathrm{~mm}$. $184 \times 207 \mathrm{~mm}(300 \times 300 \mathrm{DPI})$ 


1
2
3
4
5
6
7
8
9
10
11
12
13
14
15
16
17
18
19
20
21
22
23
24
25
26
27
28
29
30
31
32
33
34
35
36
37
38
39
40
41
42
43
44
45
46
47
48
49
50
51
52
53
54
55
56
57
58
59
60

\footnotetext{
Cladogram showing the relationships among the species of Protachyoryctes, Eicooryctes and Tachyoryctes and the phylogenetic position of Tachyoryctes makooka (matrix in Supplementary File 2). Bremer and Relative Bremer Indices are showed at the appropriate nodes. $160 \times 119 \mathrm{~mm}(300 \times 300 \mathrm{DPI})$
} 


\section{Supplementary File 1}

Characters used in the phylogenetic analysis. 8 characters are binary whereas 8 are multistate, polarity of character determined by outgroup comparison with Rhizomyides sivalensis.

1. Hypsodonty: (0) moderate; (1) high; (2) very high

2. Size: Length of the $\mathrm{m} 2$ : (0) $1.5-2.5 \mathrm{~mm}$; (1) $2.5-3.5 \mathrm{~mm}$; (2) $3.5-4.5 \mathrm{~mm}$; (3) $4.5-$

$5.5 \mathrm{~mm} ;(4)>5.5 \mathrm{~mm}$

m1

3. Mure: (0) present; (1) constricted; (2) absent

4. Mesolophid: (0) long; (1) short and migrated towards the hypolophid; (2) completely fused with the hypolophid

5. protoconid-metaconid connexion: (0) posterior; (1) anterior; (2) absent

$\mathbf{m} 2$

6. Mure: (0) present; (1) constricted; (2) absent

7. Mesolophid: (0) long; (1) short and migrated towards the hypolophid; (2) completely fused with the hypolophid

m3

8. Mure. (0) present; (1) absent

9. Mesolophid: (0) short and migrated towards the hypolophid; (1) completely fused with the hypolophid 
10. Posterosinusid: (0) large; (1) small; (2) absent (posterolophid fused with hypolophid)

11. Anterosinusid: (0) present; (1) absent

\section{M1}

12. (0) Rooted; (1) hypselodont

13. Protosinus: (0) present; (1) absent

14. Mure: (0) present; (1) absent

M2

15. Longitudinal crest: (0) present; (1) absent

M3

16. (0) reduced; (1) enlarged 


\section{Supplementary File 2}

Character/taxon matrix used in the analysis of relationships of the Tachyorictini.

Characters are listed in Appendix 1. Character scoring: 0, 1 and 2, conditions of character; ?, character state uncertain.

\begin{tabular}{|l|c|c|c|c|c|c|c|c|c|c|c|c|c|c|c|c|}
\hline & $\mathbf{1}$ & $\mathbf{2}$ & $\mathbf{3}$ & $\mathbf{4}$ & $\mathbf{5}$ & $\mathbf{6}$ & $\mathbf{7}$ & $\mathbf{8}$ & $\mathbf{9}$ & $\mathbf{1 0}$ & $\mathbf{1 1}$ & $\mathbf{1 2}$ & $\mathbf{1 3}$ & $\mathbf{1 4}$ & $\mathbf{1 5}$ & $\mathbf{1 6}$ \\
\hline Rhizomyides sivalensis & 0 & 3 & 0 & 0 & 0 & 0 & 0 & 0 & 0 & 0 & 0 & 0 & 0 & 0 & 0 & 0 \\
\hline Protachyoryctes tatroti & 0 & 2 & 0 & 1 & 1 & 1 & 1 & 0 & 0 & 0 & 0 & 0 & 0 & 0 & 0 & $?$ \\
\hline Tachyoryctes makooka & 0 & $1 \& 2$ & 1 & 1 & 0 & 1 & 1 & 0 & 0 & 0 & 0 & 0 & 0 & 0 & 0 & 0 \\
\hline Eicooryctes kaulialensis & 1 & 1 & 1 & 1 & 0 & 1 & $1 \& 2$ & 0 & 1 & 0 & $?$ & 0 & 1 & 0 & 0 & $?$ \\
\hline Tachyoryctes pliocaenicus & 1 & $0 \& 1$ & 2 & 1 & 0 & $1 \& 2$ & $1 \& 2$ & 1 & 1 & 1 & 1 & 1 & 1 & 1 & 1 & 1 \\
\hline Tachyoryctes konjiti & 1 & 1 & 2 & 2 & 1 & 2 & 2 & 1 & 1 & 2 & 1 & 1 & 1 & 1 & 1 & 1 \\
\hline Tachyoryctes macrocephalus & 2 & 2 & 2 & 2 & 2 & 2 & 2 & 1 & 1 & 2 & 1 & 1 & 1 & 1 & 1 & 1 \\
\hline Tachyoryctes splendens & 2 & $0 \& 1$ & 2 & 2 & 2 & 2 & 2 & 1 & 1 & 2 & 1 & 1 & 1 & 1 & 1 & 1 \\
\hline
\end{tabular}

